\title{
A dialética da crise do jornalismo: o sociometabolismo do capital e seus limites estruturais ${ }^{1}$
}

The dialectic of journalism crisis: the social metabolism of the capital and its structural limits

La dialéctica de la crisis del periodismo: el sociometabolismo del capital y sus límites estructurales

DOI: 10.1590/1809-5844201823

\section{Rafael Bellan Rodrigues de Souza ${ }^{1}$}

https://orcid.org/0000-0003-0165-2927

${ }_{1}^{1}$ (Universidade Federal do Espírito Santo, Centro de Artes, Programa de Pós-Graduação em Comunicação e Territorialidades. Vitória - ES, Brasil)

\section{Resumo}

Para muitos pesquisadores da comunicação, a crise pela qual passa o jornalismo é um produto de contradições subjacentes à própria profissão. Neste artigo, apostamos em outra interpretação, tendo como direcionamento metodológico uma abordagem dialética. Evidencia-se, assim, que, embora possua particularidades próprias, muitos dos sintomas da “crise do jornalismo” são consequências da crise estrutural do capital. Essa, articula, via cooperação complexa, inovações tecnológicas e gerenciais, intensificando a subsunção do trabalho vivo ao sistema de metabolismo social vigente. O desemprego crônico, a decadência ideológica, a barbárie social e a queda da taxa de lucros das mercadorias são fenômenos que afetam diretamente a prática jornalística.

Palavras-chave: Teoria do Jornalismo. Capital. Trabalho. Marxismo. Crise.

\begin{abstract}
For many communication researchers, the journalism crisis now facing is a product of contradictions underlying the profession itself. In this article, we bet on another interpretation, having the methodological guidance in a dialectical approach. It is evident, therefore, that, although it has its own peculiarities, many of the symptoms of "journalism crisis" are consequences of the structural crisis of capital. This articulates via complex cooperation, technological and managerial innovations, increasing the subsumption of living labor to the current social metabolism system. Chronic unemployment, ideological decay, social barbarism and fall of commodities profit rate are phenomena that directly affect journalistic practice.
\end{abstract}

Keywords: Theory of Journalism. Capital. Work. Marxism. Crisis.

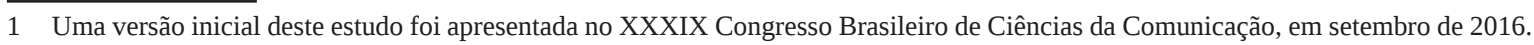




\section{Resumen}

Para muchos investigadores de la comunicación, la crisis que se enfrenta el periodismo es un producto de las contradicciones que subyacen a la profesión misma. En este artículo, se apostó por otra interpretación, la orientación metodológica de un enfoque dialéctico. Es evidente, por tanto, que, aunque tiene sus propias peculiaridades, muchos de los síntomas de la “crisis del periodismo” son consecuencias de la crisis estructural del capital. Esto se articula a través de la cooperación compleja, las innovaciones tecnológicas y de gestión, el aumento de la subsunción del trabajo vivo al sistema de metabolismo social actual. El desempleo crónico, la decadencia ideológica, la barbarie social y la caída de la tasa de ganancia de las mercancias son fenómenos que afectan directamente a la práctica periodística.

Palabras clave: Teoría del Periodismo. Capital. Trabajo. Marxismo. Crisis.

\section{Introdução}

Nosso objetivo nesse artigo é oferecer subsídios teóricos para uma interpretação crítica e dialética da propalada “crise do jornalismo”, demonstrando ser ela a expressão particular de um complexo mais amplo de contradições inseridas no seio do sistema de metabolismo do capital. Ainda que manifeste tendências e contradições próprias e complexas, o diagnóstico usual e hegemônico da conjuntura da esfera jornalística no século XXI tende a colocá-la como resultante de mudanças tecnológicas, o que, distante de ser uma observação falsa, ignora as estruturas subjacentes ao conjunto de alterações que, para além do campo jornalístico, tem afetado a totalidade do metabolismo social nas últimas décadas.

Compreender a realidade dinâmica do jornalismo, bem como investigar as mudanças estruturais pelas quais passa o setor, nos exige uma perspectiva crítico-dialética. Ou seja, para compreender os fenômenos sociais e, em especial, o papel do jornalismo na contemporaneidade, é fundamental relacioná-los com o todo social, visto aqui como a ordem reprodutiva material dos sujeitos em processo. O materialismo histórico apresentase como método que permite "apresentar o objeto a partir dos elementos internos da sua própria constituição, do ponto de vista das determinações que esse objeto sofre para ser o que é” (RANIERI, 2011, p.127). Como práxis, a comunicação dos homens envolve processos de conexão entre dimensões singulares, particulares e universais e, enredado em uma totalidade complexa e dinâmica, possui contradições próprias e mediações entre suas particularidades e o desenvolvimento do metabolismo total. A existência material dos indivíduos é a tônica para a possibilidade de conhecimento dos processos que o afetam. "O ser social só tem existência em sua reprodução ininterrupta; a sua substância enquanto ser é por essência uma substância que se modifica ininterruptamente” (LUKÁCS, 2013, p.147).

Analisar as características definidoras do processo pelo qual passa o jornalismo significa desnudar as mediações entre as particularidades que a definem e os processos mais gerais de uma crise que envolve a própria ordem sociometabólica do capital, em que 
o sistema alcança seus limites estruturais ao mesmo tempo em que revela sua incapacidade civilizatória. Mészáros (2002) define o sociometabolismo do capital como um complexo social abrangente e incontrolável caracterizado pela subsunção da divisão hierárquica do trabalho aos ditames do capital. O núcleo constitutivo desse sistema é formado por três dimensões fundamentais materialmente constituídas, a saber, o Estado, o trabalho e o próprio capital. Esse sistema subordina para si todas as áreas da atividade humana, sendo, nesse sentido, um complexo universal mediador dos complexos particulares, entre eles, os domínios culturais e intelectuais.

Uma pesquisa dialética deve sustentar-se na capacidade de revelar os mecanismos endógenos dos processos sociais que, ao contrário de autônomos, se articulam em um sistema conflituoso: política, economia e sociedade. Esse tipo de abordagem permite sínteses concretas no campo do Jornalismo, conforme Genro Filho (2012, p.23) já explicitara.

Um enfoque verdadeiramente dialético-materialista deve buscar a concreticidade histórica do jornalismo, captando, ao mesmo tempo, a especificidade e a generalidade do fenômeno. Deve estabelecer uma relação dialética entre o aspecto histórico transitório do fenômeno e sua dimensão histórico-ontológica. Quer dizer, entre o capitalismo (que gestou o jornalismo) e a totalidade humana em sua autoprodução. Dito de outro modo, o jornalismo não pode ser reduzido às condições de sua gênese histórica, nem à ideologia da classe que o trouxe à luz.

Nesse sentido, apresentaremos os principais epifenômenos que articulam a noção de “crise do jornalismo” e debateremos em seguida sua articulação com as transformações orgânicas que delimitam o metabolismo social em crise. De posse dos principais aspectos que incidem no quadro compósito e multifacetado do sistema do capital, será possível aprofundar os sintomas da crise estrutural do modo de reprodução social que, de forma centrífuga, exerce extremo poder sobre a vida cultural, econômica e política da humanidade (MÉSZÁROS, 2002). O encontro entre a crise estrutural e a miséria ideológica (PINASSI, 2009) nos parece definir o atual momento da história humana, que afeta de forma hegemônica todo o complexo, dos microcosmos mais singulares até a macroestrutura universalizante do sistema global. O jornalismo em crise não pode ser pensado fora dessa sistemática, sobre pena de permanecerem incompreendidas tanto suas limitações quanto suas potencialidades no sentido da plena realização da sociabilidade humana.

\section{O jornalismo explodiu?}

Há uma inegável crise no modelo da imprensa global até então imperante. O crescimento da Internet gerou uma clara mudança no papel reservado aos jornalistas em 
produzir, divulgar informação, com a expertise própria de uma profissão cuja estabilidade permitia o desenvolvimento e venda da mercadoria notícia. A mudança mais imponente está na circulação da informação jornalística. Hoje, ela mais se assemelha a um fluido que percorre canais cada vez mais reticulares do que uma unidade, produto moldado pela indústria das consciências (ENZENSBERGER, 2003). O modelo econômico fordista de criação, que imitava a lógica industrial da modernidade capitalista, foi alterado e a própria prática jornalística necessita de uma readequação. “A lógica da informação online é lançar uma informação em estado bruto (ou às vezes, até aproximativo) e, depois, corrigi-la, modificá-la ou enriquecê-la incessantemente, a cada hora, a cada instante...” (RAMONET, 2012, p.17).

Com a ascensão dos prodsumidores (usuários consumidores e criadores de conteúdos) há um questionamento cada vez maior do papel dos jornalistas na elaboração de narrativas noticiosas. Essa crise de identidade soma-se a uma constante e gradual perda de credibilidade das mídias convencionais que, por assumir uma lógica mercantil acelerada, tem proporcionado o esvaziamento de seu poder investigativo. $\mathrm{O}$ antigo quarto poder se rendeu às estratégias apologistas de seus financiadores e, alterando os objetivos mais nobres do Iluminismo (MORETZSOHN, 2007) em auxiliar os processos democráticos, tem se direcionado à diminuição do espaço da multiplicidade de opiniões e do papel de elaborar informação capaz de auxiliar sujeitos autônomos. O muro de informação também auxiliou essa perda de credibilidade das mídias: com hiperabundância de dados, há um bloqueio de acesso ao conhecimento, principalmente pela mídia ter assumido, sem titubear, seu papel enquanto aparelho ideológico da globalização.

Para Ramonet (2012) e para o famoso relatório da Universidade de Columbia (ANDERSON; BELL; SHIRKY, 2013) trata-se de uma mudança de ecossistema midiático, que abala as bases que definiam até então o jornalismo. Nossa questão aqui é se esse conjunto de alterações não seria também um epifenômeno de uma mudança de dinâmica global da ordem reprodutiva.

No Brasil, Pereira e Adghirni (2011, p.52) falam que “mudanças profundas afetam diferentes dimensões do jornalismo, alterando radicalmente a forma como será praticado no futuro”. Os autores atrelam três grandes transformações que afetam o cenário do jornalismo: mudança na forma de produzir notícia, mudança no perfil dos jornalistas e alterações na relação dos jornais com o público. Para eles, “as receitas das mídias convencionais estão caindo pela redução no número de leitores, pela falta de credibilidade e pela migração da publicidade para a web” (PEREIRA; ADGHIRNI, p.40). Ainda que apresentem com clareza um debate de escopo estrutural, não há questionamentos mais universais das relações existentes entre essas transformações e a ordem global reprodutiva sistêmica. Contudo, eles apontam o fenômeno mais empírico, revelando aspectos singulares do movimento “tectônico” no campo jornalístico, apontando, de forma otimista, o aparecimento de novos 
arranjos nos três eixos debatidos por eles. Isso porque os autores anteveem um grande acordo entre os envolvidos neste cenário, o que geraria uma nova estabilidade na estrutura.

Podemos, então, assumir que a famosa "crise dos jornais" não passa de um mito. Na verdade, os dados sugerem um ligeiro deslocamento dos leitores dos meios tradicionais para as mídias on-line e digitais - do mesmo jeito que o mercado de trabalho evidencia um deslocamento dos jornalistas para os setores de comunicação institucional. A velocidade desse processo e as consequências dele, contudo, são difíceis de mensurar. Ou seja, seria precipitado dizer que os jornais estão em vias de extinção ou que serão substituídos pelas novas plataformas noticiosas (PEREIRA; ADGHIRNI, 2011, p.50).

Para Salaverría (2015), menos focado no debate sobre a necessidade ou não de notícias e mais preocupado em compreender a crise estrutural do setor, há dois processos em tela: uma crise de acumulação (que envolve toda a economia mundial) e uma crise tecnológica (conectada a mudança do paradigma analógico para o digital). Sobre a primeira, ele elucida como as bases do "público” afetam a imprensa:

A redução do poder aquisitivo dos cidadãos fez que estes decidam com muito mais cuidado onde gastar seu dinheiro. E nesta atitude ficam especialmente prejudicados os produtos culturais como os oferecidos pelos meios de comunicação: entre o pão e o jornal, o dinheiro vai para o pão. Ao mesmo tempo, a deterioração de todos os setores econômicos fechou a torneira do investimento publicitário, dobrando a redução nas contas de ingresso das empresas jornalísticas (SALAVERRÍA, 2015, p.80).

Na concepção de crise tecnológica, Salaverría (2015) diz se tratar de algo menos cíclico e passageiro (a forma como ele enxerga as crises econômicas) e vislumbra que o jogo do jornalismo mudou. A digitalização criou rachaduras importantes que alteram substantivamente o jornalismo enquanto um “negócio”: ruptura de fronteiras (a digitalização internacionalizou o mercado de mídia, sem monopólio), ruptura de barreiras (há um novo mercado disponível e o barateamento dos custos de produção), ruptura do ciclo editorial (os suportes digitais exigem inúmeros produtos editoriais), ruptura do monopólio da palavra (horizontalidade entre produtores e receptores, controle social) e, por fim, ruptura do modelo de negócios (as dificuldades de sustentação econômica e a queda das vendas é algo visível). Nesse ínterim, as organizações jornalísticas tendem à ruína. Contudo, o autor acredita que a redefinição dos modos de informar deva ser a exigência mais emergencial nesses novos tempos, embora ainda aponte a necessidade de uma nova forma de sustentação financeira para o novo paradigma. 
Serrano (2013) destaca aspectos da crise do jornalismo: crise de mediação, crise de credibilidade, crise de objetividade, crise de autoridade, crise de informação, crise de distribuição. Com outro cariz, o pesquisador aponta nuances que já têm sido colocadas em relevo por diversos autores: atenção direcionada ao contexto tecnológico e comercial e, no caso específico de Serrano (2013), crítica à própria incompetência das grandes empresas em não produzirem informação de qualidade.

Também admirando as positividades desse momento de crise, Viana (2013) vê com bons olhos a derrocada dos grandes conglomerados jornalísticos. Como a indústria fonográfica, que foi extremamente modificada pela Internet, com a drástica queda na venda de CDs, ela acredita que o jornalismo, no mesmo sentido que a música, não vai desaparecer. Ela é uma das fundadoras da Agência Pública, site que investe em reportagens investigativas com o patrocínio de fundações e crowdfundings (a antiga vaquinha) e defende os novos arranjos econômicos de projetos independentes como saídas para o setor. Contudo, no oceano de mídias, cabe uma avaliação mais densa sobre o papel desses empreendimentos e do seu conteúdo como uma navegação segura pelas informações disponíveis na rede.

Em sintonia com essa visão, Anderson, Bell e Shirky (2013) apontam inúmeras previsões e soluções para o setor e a principal defesa é que o jornalismo precisa assumir novas características caso queira enfrentar o terremoto em seu ecossistema. Nessa abordagem, a entrada dos softwares que aprimoram a busca de dados e a colaboração inescapável das fontes e das audiências-ativas devem se tornar virtudes. Contudo, o cenário de uma empregabilidade e estabilidade profissional sonhada por muitos estudantes da Comunicação teria que ser substituída pela verve “empreendedora”, em que os profissionais viveriam de “projetos” efêmeros. Em outros ramos da economia, constata-se a proletarização desses “produtores”, com rotinas não muito diferentes dos assalariados precarizados.

\section{Crise estrutural do capital e desemprego crônico}

Um dos aspectos de maior destaque entre os analistas do jornalismo no século XXI é a redução explosiva do número de profissionais contratados. Pelo mundo afora os dados das demissões crescem a cada dia. Segundo Ramonet (2012), entre 2008 e 2010 a imprensa diária dos EUA demitiu mais de 25 mil jornalistas, na Espanha foram mais de 3.500, enquanto na Suíça, Bélgica, Itália e Alemanha se avolumam centenas de desempregados do setor. No Brasil, segundo a Agência Volt de Jornalismo de Dados, em pouco mais de três anos (2012 a junho de 2015), foram contabilizadas pelo menos 1.084 demissões de jornalistas em cerca de 50 redações, incluindo as principais empresas de comunicação brasileiras, a grande maioria por cortes de custos. Os chamados passaralhos (demissões em massa) mostram claramente o mecanismo de enxugamento do trabalho vivo aplicado à produção jornalística. 
Nas redações a reestruturação é geral, os sistemas de dados e os bancos de informação são interligados, e com isso a pesquisa e a apuração mudam de ritmo, de forma e de estrutura. Muitas funções desaparecem. As reformas gráficas com cores e formatos enxutos passam a protagonizar as marcas das empresas jornalísticas. Entram no mercado as agências de comunicação que fornecem serviços de relações públicas e assessoria de comunicação (FIGARO, 2015, p.31).

A mudança no perfil dos profissionais evidencia a feminização dos postos de trabalho e uma intensificação das horas trabalhadas, sendo que a maior parte dos profissionais se desdobram em mais de uma atividade e emprego. Eles são assessores, freelancers, repórteres... trabalham de oito a dez horas por dia e a maioria é jovem (até 35 anos). Amplia-se também a pejotização, em que os contratos realizados pelas empresas a eximem dos tributos relativos aos direitos do empregado (FIGARO; LIMA; GROHMANN, 2013). A fragilidade de princípios ideológicos críticos é similar a precarização do trabalho jornalístico, algo atestado nas pesquisas de Fígaro (2015) e Mick e Lima (2013).

São cada vez mais nítidas as expressões de uma reestruturação produtiva no trabalho jornalístico. Algo que, na linha toyotista, fragmenta e precariza as atividades laborais, intensificando o estranhamento. O contexto de flexibilização profissional perpassa os conglomerados de mídia, que readequam suas rotinas produtivas a reestruturação, atribuindo aos jornalistas novas funções que jogam nas suas costas as variações do mercado de informação. Mão de obra precarizada, com jornadas de trabalho flexíveis, contratos sem garantias - temporários e autônomos - os trabalhadores do conhecimento (HUWS, 2013) são parte dessa nova condição da classe trabalhadora. A reestruturação produtiva da classeque-vive-do-trabalho (ANTUNES, 1999), bem como o desemprego estrutural e a miséria ideológica de uma sociedade de informações fetichizadas são expressões fenomênicas da crise estrutural do capital.

Regras flexíveis querem dizer “a precarização da força de trabalho no mais alto grau praticável, na esperança de melhorar as perspectivas de acumulação lucrativa do capital, enquanto se finge uma preocupação com a garantia dos empregos e com a redução do desemprego” (MÉSZÁROS, 2002, p.330). Essa realidade, infelizmente, não é própria dos jornalistas, o que se vê em cena desde meados da década de 1970 é a tentativa de rearticular o mundo do trabalho para aumentar o grau de lucratividade perdida, uma ação combinada de articulação entre inovações tecnológicas e gerenciais e a equalização da taxa de exploração global. O Estado de Bem-Estar Social mostrou-se incapaz de conter essas mudanças.

Pois uma coisa é imaginar o alívio ou a remoção do impacto negativo do desemprego em massa de um, ou mesmo mais de um, país particular mediante a transferência de sua carga para alguma outra parte do mundo, 
ao “melhorar a posição competitiva” do país ou dos países em questão: um remédio tradicional nos textos, de que até hoje se ouve falar. Entretanto, outra coisa completamente diferente é sonhar com essa solução quando a doença afeta todo o sistema, estabelecendo um limite óbvio ao que um país pode fazer para “mendigar ao vizinho”, ou mesmo o resto do mundo, caso se trate do país hegemônico mais poderoso, caso dos Estados Unidos no período posterior à Segunda Guerra Mundial. Sob essas circunstâncias, ativa-se a "explosão populacional”, sob a forma de desemprego crônico, como um limite absoluto do capital (MÉSZÁROS, 2002, p.333).

Isso ocorre porque há uma queda tendencial da taxa média de lucros no interior do sistema do capital, resultante do aumento de sua composição orgânica. Outro aspecto vital na leitura de Mészáros (2002) é a taxa decrescente de bens e serviços socialmente produzidos, bem como a destruição ambiental avassaladora e a barbárie social advinda da intensificação das desigualdades sociais. Há também a financeirização da riqueza capitalista, que dá a tônica da mundialização do capital. Algumas características permitem a diferenciação da crise estrutural vigente das meras crises episódicas e cíclicas do capital.

(1) seu caráter é universal, em lugar de restrito a uma esfera particular (por exemplo, financeira ou comercial, ou afetando este ou aquele ramo particular de produção, aplicando-se a este e não àquele tipo de trabalho, com sua gama específica de habilidades e graus de produtividade etc.);

(2) seu alcance é verdadeiramente global (no sentido mais literal e ameaçador do termo), em lugar de limitado a um conjunto particular de países (como foram todas as principais crises no passado);

(3) sua escala de tempo é extensa, contínua, se preferir, permanente, em lugar de limitada e cíclica, como foram todas as crises anteriores do capital;

(4) em contraste com as erupções e os colapsos mais espetaculares e dramáticos do passado, seu modo de se desdobrar poderia ser chamado de rastejante, desde que acrescentemos a ressalva de que nem sequer as convulsões mais veementes ou violentas poderiam ser excluídas no que se refere ao futuro: a saber, quando a complexa maquinaria agora ativamente empenhada na "administração da crise” e no "deslocamento” mais ou menos temporário das crescentes contradições perder sua energia (MÉSZÁROS, 2002, p.795-796).

Uma crise estrutural é aquela que cobre a totalidade de um sistema, afetando suas partes constitutivas e os complexos a ele relacionados. Somente é possível o deslocamento das contradições de uma crise enquanto ela for parcial. Nos processos que compõem uma crise sistêmica estrutural, todos seus limites são desafiados e, nesse sentido, sua estrutura passa a ser corrompida. Ora, a destruição de matéria prima, bem como da própria humanidade 
vitimada pela dimensão corrosiva e incivilizatória dos dispositivos incontroláveis da ordem metabólica do capital, inserem-se num processo de intensificação do polo negativo da destrutividade capitalista. As três dimensões fundamentais do capital - produção, consumo e circulação/distribuição/realização - são motivados por autoexpansão, sendo que no contexto de crise estrutural eles encontram suas próprias barreiras intransponíveis. "Quem acha que isto soa muito dramático deveria olhar à sua volta, em todas as direções. É possível encontrar qualquer esfera de atividade ou qualquer conjunto de relações humanas não afetado pela crise?” (MÉSZÁROS, 2002, p.800).

Contudo, considerar a crise estrutural do capital como uma realidade da ordem de reprodução metabólica não significa prever o fim do sistema e o nascimento de um novo e alegre dia seguinte de uma sociedade emancipada. Não há nenhuma garantia de melhora automática pós-derrocada do capital, como o sistema é composto pela própria humanidade, sua ruína é sinônimo de uma desumanização em escala sem precedentes. Alves (2011) trata da expressão cada dia mais grave do sociometabolismo da barbárie, ou seja, de como a acumulação flexível exige mudanças que congregam avanços tecnológicos e organizacionais no sentido de intensificar a valorização do capital. Ele desenha também os aportes ideológicos desse processo, denominando o toyotismo como a ideologia orgânica do sistema de metabolismo social.

A ordem reprodutiva do capital e sua atual divisão do trabalho tem se apropriado da “revolução" informacional, colocando a rede digital como mediadora principal da produção, no âmbito do trabalho, do lazer e do consumo. Como apontam Frederico e Teixeira (2008), a cooperação complexa fornece a tônica dessa dinâmica do capital. Há uma poderosa interação entre os trabalhos produtivos e improdutivos, materiais e não-materiais, intelectuais e braçais, o que torna muito difícil a compreensão da criação de valor e extração de mais-valor. A cooperação complexa seria um modo de controle da produção social que intensifica a subsunção do trabalho ao capital, via maquinaria e tecnologias informacionais. Pelos limites desse artigo não podemos caracterizar o papel do trabalho jornalístico, mas acreditamos que as descobertas de Fuchs (2015) são insights importantes da conexão existente entre as atividades de produção de conteúdo e a rede que chega até os extratores de minérios presentes em laptops e smartphones. Ou seja, a extração de valor do trabalho vivo está ligada a uma grande maquinaria global inter-relacionada, o que precisa ser levado em conta ao pensarmos as especificidades da crise do jornalismo². Como aponta Huws (2013, p.39) não podemos ignorar "que pessoas reais com corpos reais têm contribuído em tempo real para o desenvolvimento destas mercadorias “imateriais"”.

2 Em tempos de cooperação complexa do capitalismo contemporâneo, o valor é definido pelo trabalho coletivo inter-relacionado em cadeias produtivas mundiais. Isso significa que o trabalho digital, informacional, não existiria sem uma infraestrutura material gerada por trabalhadores remunerados em territorialidades de dimensão global. A força de trabalho (combinando o labor físico e cultural) em sua articulação com os meios de produção são os alicerces do capitalismo financeiro hegemônico. 
Em síntese, há uma relação complexa entre os passaralhos e o desemprego crônico advindo da crise estrutural que envolve os mecanismos metabólicos de reprodução do capital. A reestruturação do mundo do trabalho e as mudanças organizacionais, expressas também pelas inovações tecnológicas direcionam-se a uma tentativa de recuperar os lucros cada vez menores, consequência da dinâmica incontrolável do capital em fase de acumulação flexível e financeirização da economia (HARVEY, 1993). Todas as formas de indústria passaram por processos semelhantes e, longe de abraçar a tese de que vivemos em uma sociedade pós-industrial, há de fato um redesenho da dinâmica capitalista na cooperação complexa, ocasionando uma nova morfologia do trabalho e um novo contexto para a disseminação de mercadorias, principalmente em uma defasagem do valor de troca de produtos, hipertrofiados no mercado.

\section{Crise das formas de conhecimento}

Há no interior desse processo de crise evidentes dimensões relacionadas à função das tecnologias na cooperação complexa exigida pelo capital em crise. A digitalização da vida social e da reprodução humana coloniza e toma conta do cotidiano, alterando a compreensão sobre o tempo livre e o substituindo por tempo de consumo, lazer e atividades atreladas ao sistema metabólico (pense nas ações de pagamento de contas e resolução de problemas técnicos assumidos pelos consumidores, e no tempo não remunerado de milhares de jovens que disponibilizam informações na rede). Embora abra leque para possibilidades comunicativas até então impensadas (ou aproximadamente sonhadas por filósofos como Enzensberger (2003), por exemplo), a Internet, e a digitalização ampla pela qual passa a sociedade, não pode ser fetichizada. Ela é parte determinante/determinada da ordem sociometabólica do capital, mesmo que, contraditoriamente, possibilite a ampliação de certas sociabilidades até então inexistentes.

De fato, a massa de mídias (RAMONET, 2012), ao disponibilizar mecanismos de expressão social mais livre (mesmo que possibilitando alto grau de vigilância) abre espaço para a revelação das contradições. O ativismo comunicacional nas redes sociais e na esfera digital tem se ampliado, mas mesmo eles, ao se organizarem em plataformas, sites, softwares e usufruírem de satélites, cabos, computadores, celulares, enfim, produtos desenvolvidos na lógica do capital e produzidas de forma industrial, em sua estrutura, não negam objetivamente a ordem vigente, muito pelo contrário.

A mídia se apropria de diferentes léxicos para tentar colocar dentro de si todos os léxicos, a serviço de objetivos particulares. Palavras e expressões que pertenciam tradicionalmente ao léxico da esquerda (reforma, inclusão, transformação social, revolução) foram usurpadas pelo conservadorismo e ressignificadas pelos discursos pró-mercado, sobretudo no auge da hegemonia 
do neoliberalismo, nas décadas de 1980, 1990 e parte de 2000 (MORAES, 2016, p.115).

Os produtos jornalísticos têm perdido seu valor de troca exatamente por terem de competir com as mais variadas formas de infotenimento, que povoam o cotidiano da audiênciaativa, cada vez mais conectada em convergências midiáticas pautadas no espetáculo. O jornalismo visto como narrativa de uma sociedade democrática, bastião do estado de direito e vigilante dos poderes parece cada vez mais fora de lugar. Em uma sociedade cada dia mais desumana (cuja crise estrutural revela a incivilidade e irreformalidade do capital), como manter o valor de uso cultivado na modernidade? Como recuperar um tempo em que a revolução industrial e os ideais da república demandavam uma mercadoria dinamizadora da esfera pública?

A crise do valor de troca implica uma crise de valor de uso da notícia, isso porque há um crescimento exponencial - potencializado pela “sociedade em rede” - da miséria ideológica. A mercadoria jornalística entendida como esteio de transformações de consciência e formação de cidadãos para um capitalismo em ascensão não corresponde mais às necessidades de consumo de uma multidão estranhada que é suporte de um capital em crise. A escassez no oferecimento desse tipo de produto noticioso foi se intensificando com o progressivo encurtamento do tempo de produção noticiosa e a derrocada do quarto-poder. O jornalismo sentado, especializado em coberturas tendenciosas das classes dominantes e/ ou conectadas ao entretenimento e a diversão, já começou a sepultar o ideal republicano que inspirou o status que a profissão tinha. Ainda que não generalizada, a decadência ideológica (LUKÁCS, 2009) de uma burguesia que antes assumira o progresso e a emancipação humana e, que, tornara-se apologética da exploração capitalista, expressou-se também na prática jornalística.

Para Pinassi (2009) a crise estrutural do capital encontra a miséria ideológica como seu corolário. Essa decadência se evidência pelo alto grau de corrosão que todas as formas de conhecimento têm sofrido nas últimas décadas. Esvaziamento de conteúdo e distorção gerada pelo irracionalismo e por incrustações neopositivistas, norteadas pelo individualismo e na manutenção da ordem social são a tônica ideológica desse momento histórico. Vale notar que teóricos de diferentes matrizes têm percebido, de um ponto de vista crítico, o estranhamento subjetivo do capitalismo tardio, desde o novo espírito do capitalismo de Boltanski e Chiapello (2009); a corrosão do caráter de Sennet (2009); a captura da subjetividade de Alves (2011); a nova razão do mundo, o neoliberalismo, de Dardot e Laval (2016), entre outros. Evidente que com singularidades distintas, colocando em relevo certas mediações em detrimento de outras, o importante aqui, sem querer achatar a diversidade desses pensamentos, é anunciar o mal-estar da subjetividade estranhada pelo modelo econômico em voga. 
Esses processos de esvaziamento no campo dos conhecimentos (cuja universalização iluminista foi abandonada pela burguesia apologética), somado ao irracionalismo pósmoderno que avança na academia e no senso comum, bem como a subsunção da subjetividade da classe-que-vive-do-trabalho aos dogmas do neoliberalismo e seus mantras do "homemempresa”, e o empreendedorismo como discurso do individualismo concorrencial do capitalismo manipulatório são expressões da crise mais ampla e destrutiva do capital. Barbárie social, miséria ideológica e corrosão do trabalho vivo afetam o sistema midiático e também a prática jornalística.

Enumerar, todavia, a existência de uma articulação profunda entre a crise estrutural do capital e a decadência ideológica e como ela impacta na circulação e produção da informação jornalística não significa abraçar o pessimismo. O que deve ser percebido e refletido constantemente é o desgaste do valor de uso de um tipo de mercadoria capaz de produzir sujeitos autônomos para um capitalismo desenvolvido e de feições “humanas”. Para Mészáros (2002), não há solução possível dos graves problemas da ordem de reprodução metabólica do capital dentro do próprio sistema.

A singularidade reificada, expressa pelo jornalismo burguês, agora foi absorvida pelo senso comum espontâneo das massas. O papel ideológico reformista de defesa de um “capitalismo humanizado” progressista, desenvolvido, típico de uma burguesia revolucionária (algo real no século XIX) parece não mais ter lugar. Nesse momento de graves problemas sociais, a humanidade precisa de muito mais do que isso.

\section{Considerações Finais}

Mesmo nesse contexto explicitado, que revela as mediações contraditórias existentes entre a precarização dos trabalhadores do conhecimento; o lugar das tecnologias na reprodução do capital em cooperação complexa; e o esvaziamento, dado pelo infotenimento e pela rapidez no fluxo de informações - sintoma da decadência ideológica - dos conteúdos jornalísticos, vemos que essa prática não foi extinta. Mas por que, como uma fênix que ressurge das cinzas, o jornalismo seria necessário?

Apostamos que o valor de uso do jornalismo está na sua capacidade de desestabilizar os consensos e desmistificar a realidade reificada no sentido de superá-la. A essência do jornalismo enquanto forma social de conhecimento (GENRO FILHO, 2012) o coloca, junto à ciência e às artes, como uma necessidade vital para o reconhecimento da realidade em que vivemos. Equivocadamente tem-se na leitura desse expoente dos estudos jornalísticos brasileiros a compreensão de que qualquer forma de notícia seria um relevante conhecimento cristalizado nos aspectos singulares da realidade. Não obstante, a crítica que Genro Filho (2012) faz ao singular reificado veiculado em muitos produtos da imprensa burguesa atesta que sua análise aponta para um tipo de jornalismo diferente, que resistiria até mesmo com a 
derrocada do sistema capitalista que o produziu. A predominância hegemônica de um presente contínuo sem horizontes, em que os estranhamentos dos indivíduos se potencializam na esfera reticular, essa cegueira branca metaforizada por Saramago (1995), precisa de uma substantiva intervenção crítica. O jornalista como mediador social capaz de promover, de forma realista, a relação entre os aspectos singulares e sua dimensão totalizante, não é apenas necessário, mas imprescindível caso queiramos inserir na totalidade social um novo metabolismo social.

Longe de colocar um projeto cuja práxis no atual contexto seria irreal, concordamos com Moretzsohn (2007) que há situações em que o trabalho crítico e criativo nega o caráter estranhado da estrutura em que é produzido, visto que o capital e seus mecanismos de corrosão tanto da subjetividade, quanto da prática jornalística, nunca é integral, total. Ampliar as fissuras existentes no sistema, que passa por uma crise estrutural, no sentido de contribuir para a potencialização das transformações imprescindíveis é um passo fundamental a ser tomado.

O jornalismo crítico emancipatório não está restrito a mera defesa de um programa, seja reformista ou revolucionário, ele está associado a pressupostos ontológicos e ideológicos capazes de permitir a abstração fundamental e dialética do desnudamento da reificação capitalista. O ponto de chegada desse jornalismo, enunciando em uma narrativa o singular, torna-se conhecimento ao permitir pistas das contradições do metabolismo social. Realista, esse tipo de relato do mundo objetivo possui um valor para além das necessidades orgânicas do capital, visto que seria seu anteverso, a antecipação de uma outra sociabilidade. Não cabe expor aqui, pelos limites desse artigo, exemplos dessa práxis jornalística. Contudo, pode-se perceber expressões da produção dessa singularidade - que aponta para uma crítica do existente - em variadas notícias e reportagens disponíveis tanto na mídia convencional, como também no interior de produtos dos novos coletivos jornalísticos e nas mídias radicais alternativas (DOWNING, 2002). O elemento a destacar é que, mesmo em situações de controle e precarização, as brechas no sistema sempre estão presentes, parte das contradições do sistema metabólico, e cabe ao jornalista crítico alargá-las. "Pensar contra os fatos significa preservar a relação do jornalismo com o imediato, imprimindolhe o duplo movimento de abranger a floresta a partir das árvores para revelá-las em sua conexão singular com o universo a que elas pertencem” (MORETZSONH, 2007, p.289).

Quando Enzensberger (2003) relatava a potencialidade da mídia em permitir a popularização da produção coletiva, em que cada receptor seria um transmissor em potencial e que o controle dos meios socializados permitiria a aprendizagem política, ele não imaginava que esse processo seria instituído pela própria maquinaria capitalista. Isso estancou essa potencialidade dentro dos limites da ordem em crise, democratizando a decadência ideológica. Quando finalmente as pessoas podem ter uma tecnologia avançada de produção comunicacional voltada a criar conteúdos para o mundo, sua decisão estranhada é volta-la para si próprias, em selfs, tweets, snapchats e blogs narcisistas. 
Muito próxima da educação, em sua tarefa de elaboração de uma contra consciência, cabe aos jornalistas direcionar o aspecto criador de seu trabalho na constituição de uma forma realista de práxis noticiosa e, para além de sua particularidade profissional, atuar na composição coletiva do trabalho como alternativa hegemônica ao capital. As mediações para a construção desse profissional perpassam a esfera da universidade, mas também o constante aprendizado junto aos que lutam por uma sociedade diferente, papel que inclui os movimentos sociais, partidos revolucionários e organizações anticapitalistas.

Assim como os educadores são essenciais para a catarse - elevação da condição egoístico-passional para a ético-política (GRAMSCI, 2006) - os jornalistas precisam assumir a tarefa de articular de forma crítica sua práxis noticiosa, podendo ser um guia fundamental nestes tempos de caos informativo. Contudo, eles devem ter a consciência de que essa tarefa envolve mais o compromisso com o ativismo por um outro mundo possível, e necessário, do que a garantia de um status profissional seguro.

\section{Referências}

ALVES, G. Trabalho e Subjetividade: o espírito do toyotismo na era do capitalismo manipulatório. São Paulo: Boitempo, 2011.

ANDERSON, C. W.; BELL, E.; SHIRKY, C. Jornalismo Pós-industrial: adaptação aos novos tempos. Revista de Jornalismo ESPM, abr./jun. 2013, p.30-89.

ANTUNES, R. Os sentidos do trabalho: ensaio sobre a afirmação e a negação do trabalho. São Paulo: Editora Boitempo, 1999.

BOLTANSKI, L.; CHIAPELLO, É. O Novo Espírito do Capitalismo. São Paulo: Martins Fontes, 2009.

DARDOT, P.; LAVAL, C. A nova razão do mundo: ensaio sobre a sociedade neoliberal. São Paulo, Editora Boitempo, 2016.

DOWNING, J. Mídia radical: rebeldia nas comunicações e movimentos sociais. São Paulo: Editora Senac, 2002.

ENZENSBERGER, H. M. Elementos para uma teoria dos meios de comunicação. São Paulo: Conrad Editora, 2003.

FIGARO, R. Jornalismos e Trabalho de Jornalistas: desafios para as novas gerações no século XXI. Revista Parágrafo, v.2, n.2, 2015.

FIGARO, R.; LIMA, C. N.; GROHMAN, R. As mudanças no Mundo do Trabalho do Jornalista. São Paulo: Atlas, 2013.

FREDERICO, C.; TEIXEIRA, F. Marx no Século XXI. São Paulo: Cortez, 2008.

FUCHS, C. Georg Lukács as a Communications Scholar: cultural and digital labour in the context of Lukács’ ontology of social being. Media, Culture \& Society, first published on December 23, 2015.

GENRO FILHO, A. O segredo da pirâmide: para uma teoria marxista do jornalismo. Florianópolis: Editora Insular, 2012.

GRAMSCI, A. Cadernos do cárcere, v.1. Rio de Janeiro: Civilização Brasileira, 2006.

HARVEY, D. Condição Pós-Moderna. São Paulo: Loyola, 1993. 
HUWS, U. Mundo material: o mito da economia imaterial. Revista Outubro, n.21, $2^{\circ}$ sem. 2013.

LUKÁCS, G. Para uma ontologia do ser social II. São Paulo: Boitempo Editorial, 2013.

Marxismo e teoria da literatura. São Paulo: Expressão Popular, 2009.

MÉSZÁROS, I. Para além do capital. São Paulo: Boitempo Editorial, 2002.

MICK, J.; LIMA, S. O perfil do jornalista brasileiro. Florianópolis: Insular, 2013.

MORAES, D. de. Crítica da Mídia e Hegemonia Cultural. Rio de Janeiro: Mauad X, 2016.

MORETZSOHN, S. Pensando contra os fatos: jornalismo e cotidiano: do senso comum ao senso crítico. Rio de Janeiro: Revan, 2007.

PEREIRA, F. H.; ADGHIRNI, Z. L. O jornalismo em tempo de mudanças estruturais. Intexto: UFRGS, v.1, n.24, p.38-57, jan./jun. 2011.

PINASSI, M. O. Da miséria ideológica à crise do capital. São Paulo: Boitempo Editorial, 2009.

RAMONET, I. A explosão do jornalismo: das mídias de massas à massa de mídias. São Paulo: Publisher Brasil, 2012.

RANIERI, J. Trabalho e Dialética: Hegel, Marx e a teoria social do devir. São Paulo: Editora Boitempo, 2011.

SENNET, R. A corrosão do caráter. São Paulo: Editora Record, 2009.

SERRANO, P. Outro jornalismo possível na internet. MORAES, D.; RAMONET, I.; SERRANO, P. Mídia, poder e contrapoder: da concentração monopólica à democratização da informação. São Paulo: Boitempo, Rio de Janeiro: Faperj: 2013.

SALAVERRÍA, R. Mídia e jornalistas: um futuro em comum? Revista Parágrafo. v.1, n.3, jan./jun. 2015.

SARAMAGO, J. Ensaio sobre a cegueira. São Paulo: Cia das Letras, 1995.

VIANA, N. A crise do jornalismo industrial e os novos modelos de produção. Margem Esquerda - ensaios marxistas, n.20, mar. 2013, p.29-34. São Paulo: Boitempo Editorial, 2013.

\section{Rafael Bellan Rodrigues de Souza}

Professor adjunto do Departamento de Comunicação e do Programa de Pós-Graduação em Comunicação e Territorialidades da Universidade Federal do Espírito Santo (Ufes). Possui pósdoutorado no Departamento de Comunicação e Artes da Universidade de São Paulo (ECA-USP), doutorado em Ciências Sociais pela Universidade Estadual Paulista Júlio de Mesquita Filho (Unesp), mestrado em Comunicação Midiática pela Unesp (2006) e graduação em Comunicação Social Jornalismo também pela Unesp (2003). Atua como pesquisador do Observatório da Mídia e do Grupo de Pesquisa Trabalho e Práxis da Ufes e também do Centro de Pesquisa em Comunicação e Trabalho da USP (CPCT). É autor dos livros Jornalismo e Crítica de Mídia na Amazonia (Scortecci, 2016), As mídias radicais do MST (Paco, 2015) e de artigos em publicações científicas. E-mail: rafaelbellan@ yahoo.com.br.

Recebido em: 22.09.2016

Aprovado em: 16.07.2018

Este artigo é publicado em acesso aberto (Open Access) sob a licença Creative Commons Attribution Non-Commercial (CC-BY-NC), que permite uso, distribuição e reprodução em qualquer meio, sem restrições, desde que sem fins comerciais e que o trabalho original seja corretamente citado.

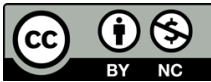

